\title{
Crítica ao manejo humano em Belo Horizonte*
}

\author{
Alexandre de Pádua Carrieri** \\ Carolina Machado Saraiva de Albuquerque Maranhão*** \\ Ivana Benevides Dutra Murta****
}

Sumário: 1. Introdução; 2. O que a mídia fala sobre o manejo humano?; 3. O shopping ou a objetivação do poder discursivo: o manejo humano; 4. Considerações finais.

Summary: 1. Introduction; 2 . What the media thinks about the human changes?; 3. The mall or the objectification of discursive power: the changing human; 4 . Final remarks.

Palavras-chave: camelôs; prefeitura; informalidade; discurso; shoppings populares.

KEY wORDs: peddlers; city hall; informal economy; discourse analysis; popular mall.

Este artigo apresenta uma visão crítica acerca da mudança dos camelôs para os denominados shoppings populares, implementados pela Prefeitura Municipal de Belo Horizonte, com a finalidade de cumprir o código de conduta do projeto "Centro Vivo".

\footnotetext{
* Artigo recebido em mar. e aceito em ago. 2008. Os autores agradecem à Fundação de Amparo à Pesquisa do Estado de Minas Gerais (Fapemig), por fomentar o projeto de pesquisa, a partir do qual foi possível a realização deste artigo. Também agradecem ao Conselho Nacional de Desenvolvimento Científico e Tecnológico (CNPq), pela concessão de bolsas de iniciação científica e de doutorado.

** Doutor em administração pelo Centro de Pós-Graduação e Pesquisas em Administração da Universidade Federal de Minas Gerais (Cepead/UFMG), coordenador do Núcleo de Estudos Organizacionais e Simbolismo (Neos), professor adjunto da UFMG. Endereço: Av. Antônio Carlos - Campus UFMG/Faculdade de Ciências Econômicas/Cepead — CEP 31270-091, Belo Horizonte, MG, Brasil. E-mail: lexandre@cepead.face.ufmg.br.

**** Mestre em administração pela Universidade Federal de Santa Catarina (UFSC) e doutoranda em administração pela UFMG. Endereço: Rua Santo Agostinho, 567, ap. 1001 — Sagrada Família — CEP 31035-480, Belo Horizonte, MG, Brasil. E-mail: carola.maranhao@gmail.com.

**** Bacharelanda em turismo pela UFMG e bolsista de iniciação científica do Programa Institucional de Bolsas de Iniciação Científica da UFMG (Probic/Fapemig). Endereço: Rua Junquilhos, 1019, ap. 202 B - Jardim América - CEP 30460-010, Belo Horizonte, MG, Brasil. E-mail: ivanabenevides@yahoo.com.br.
} 


\begin{abstract}
Argumenta-se que a atitude da prefeitura foi de limpeza da cidade, provocando uma desarticulação do trabalho informal dos camelôs e "toreros", bem como aumentando a precariedade de suas condições políticas e sociais de trabalho. O argumento baseia-se no discurso da mídia impressa e de algumas atas de reunião da prefeitura concernentes ao tema. Os autores contrastam o discurso com o dos próprios camelôs, que foram entrevistados, a respeito de como percebiam o processo de mudança para os shoppings e o que isso acarretou em termos do seu trabalho.
\end{abstract}

\title{
Critique of human handling in Belo Horizonte, Brazil
}

This article presents a critical view of how peddlers were relocated to the 'popular malls' implemented by the Municipal Government of Belo Horizonte, with the purpose of enforcing the code of project Centro Vivo. The argument is that the officials' intention of cleaning up the city caused a disarticulation of the informal work of the peddlers and 'toreros' and increased the precariousness of their social and political working conditions. The media and city hall discourses were contrasted with the discourse of the peddlers, who were interviewed regarding their perception over this phenomena and its consequences for their work.

\section{Introdução}

A problemática principal deste artigo está às voltas com a questão do trabalho informal e de sua superação. Frequentemente se atribui a origem do trabalho informal à crise do modelo fordista e, particularmente no Brasil, à deficiência na oferta de empregos devido à baixa industrialização, levando parte da população a "optar" por subempregos e condições de trabalho precárias (Noronha, 2003:118).

Independentemente de sua origem, Ribeiro (2005) argumenta que o trabalho informal deve ser encarado como uma realidade e assim serem desenvolvidos meios de inclusão social e econômica de parte da população excluída do ambiente formal. Corroborando o argumento do autor, a Organização Internacional do Trabalho - OIT (2006) afirma que a população economicamente ativa da América Latina é de 239 milhões de pessoas, sendo que 103 milhões trabalham na informalidade. Em adição, dados concedidos pelo IBGE informam que, em 2003, o Brasil possuía mais de 10 milhões de pequenas empresas informais e o estado de Minas Gerais abriga 10,3\% das empresas informais do país.

De modo geral, a formalidade-informalidade do trabalho é frequentemente encarada como uma questão de positividade-negatividade, sobre a qual os argumentos da mídia, de organizações como a OIT e o IBGE, dos trabalhos acadêmicos e os contidos nas medidas administrativas (políticas públicas), 
não tardam em apontar as benesses do trabalho formal, através do estabelecimento de vínculo direto ou indireto entre formalidade e superação da pobreza (e.g., Helal e Neves, 2007). Gontijo Neto e Machado (2003), por exemplo, evidenciam que há (sempre) uma forte tentativa do Estado em buscar formalizar o setor informal, principalmente a partir de meados dos anos de 1990.

Particularmente, em Belo Horizonte, a prefeitura colocou em prática nos últimos anos (o que se convencionou chamar de gestão de cidades) a combinação entre o Código de Posturas ${ }^{1}$ e o chamado programa Centro Vivo ${ }^{2}$ que, entre outras coisas, pretende "disciplinar" os comportamentos dos cidadãos e "revitalizar" o centro urbano da cidade, respectivamente. Conforme Zambeli (2006), o crescimento da cidade, somado a outros fatores como diminuição dos investimentos em infraestrutura, fez com que o centro da cidade fosse ocupado por pessoas com baixa qualificação, que encontraram no trabalho informal uma fonte de sobrevivência. A autora ainda indica que o poder público, em parceria com a iniciativa privada, constituiu os denominados "shoppings populares" para fazer frente à negatividade do trabalho informal realizado pelos camelôs e "toreros", ${ }^{3}$ caracterizado por: ocupação irregular do espaço público, sujeira dos passeios, baixa visibilidade das lojas comerciais formais etc. A constituição de tais shoppings significou a retirada dos trabalhadores informais das ruas e sua alocação em locais, por assim dizer, de trabalho formal. Num curto espaço de tempo fez-se vivo o centro.

Existem questões associadas a esse processo de "retirada-alocação" que não são ou não se quer explorar. $O$ tratamento que tal processo recebeu, sob a positividade da formalidade, parece ter obscurecido o entendimento que poderíamos ter dele, isto é, sobre os discursos e sobre as atividades concretas que foram realizadas. Mas não se trata de inverter meramente a polaridade na ingênua pretensão de conclamar sua negatividade. Trata-se do reconhecimento de que sua própria definição não "cai das árvores" (o trabalho informal e o formal têm a mesma origem) e que existe, portanto, uma produção discursiva

\footnotetext{
${ }^{1}$ Lei no ${ }^{\circ}$ 8.616, de 14 de julho de 2003.

2 O programa Centro Vivo "é um conjunto de obras e projetos sociais que visa à recuperação da área central de Belo Horizonte. Suas ações são focadas na inclusão social, econômica e cultural, na requalificação urbanística e ambiental, e na segurança social". Disponível em: www.vivabh. org.br/projetos.html\#Centro>. Acesso em: 13 abr. 2007.

3 "Torero" é nome dado aos camelôs (de Belo Horizonte) que foram excluídos dos shoppings populares ou preferiram resistir e continuar como ambulantes sem terreno marcado. De acordo com a declaração de um desses profissionais: "Já que a prefeitura proibiu, a gente vende assim mesmo, "na tora".
} 
e um exercício do poder em torno da constituição dos shoppings populares por um processo histórico aqui denominado de "manejo humano". Nesse sentido, o objetivo deste artigo consiste na análise crítica do processo de transferência de homens e mulheres das ruas para o Shopping Oiapoque. A análise de tal processo pretende favorecer o entendimento sem sucumbir ao romantismo ligado à sua positividade.

Para a realização de tal análise, foi necessária a incursão ao campo e a combinação de diferentes técnicas de coleta de dados. Realizamos 22 entrevistas com os trabalhadores ("ex-camelôs") e membros da administração do shopping em questão, combinando roteiro de entrevistas, as quais foram gravadas e transcritas posteriormente, e um questionário semiestruturado autorrespondende, quando não foi possível a realização de entrevista gravada. Durante as incursões, também realizamos conversas informais e observações que foram registradas em notas de campo. Em adição, buscamos informações em materiais oficiais da Prefeitura Municipal de Belo Horizonte, especialmente as atas de reunião da Câmara Municipal. Uma vez mais, coletamos as matérias que tratavam sobre os shoppings populares publicadas nos jornais da cidade, especialmente as do jornal Estado de Minas. De posse desses dados e posterior organização, optamos por estabelecer uma relação entre as matérias, entrevistas e observações que nos permitisse compreender, por um lado, os elementos presentes nos discursos produzidos pelo mencionado jornal durante cinco anos e, por outro, as atividades concretas da prefeitura e de outros membros da sociedade no processo de transferência e de utilização espacial do shopping.

Assim, estruturamos a artigo em três partes, além da introdução. $\mathrm{Na}$ sequência, apresentamos, a partir de uma análise crítica do discurso, os elementos contidos nas matérias do jornal Estado de Minas sobre o processo de transferência e acontecimentos após a instalação das pessoas no shopping. $\mathrm{Na}$ terceira parte, indicamos as atividades concretas ligadas ao processo de manejar seres humanos e quanto à utilização do espaço. Na quarta e última são tecidas as considerações finais.

\section{0 que a mídia fala sobre o manejo humano?}

Apresentamos aqui a análise crítica do discurso sobre os shoppings populares de Belo Horizonte, especialmente o Shopping Oiapoque. O foco foi em reportagens do jornal Estado de Minas, por ser este o de maior tradição e circulação do estado. Foram coletadas reportagens do período de 2003 a 2007, totalizan- 
do 83 matérias que tratavam diretamente sobre a questão da transferência dos trabalhadores informais das ruas para o shopping.

Os dados primários foram observados qualitativamente baseando-se na análise crítica de discurso (Faria, 2001; Fiorin, 1989; Maingueneau, 1998) que é composta dos seguintes elementos:

v os principais aspectos da seleção lexical;

v os principais temas e figura, incluindo os personagens;

v os principais percursos semânticos;

v outros aspectos relevantes da semântica discursiva;

- os principais aspectos da sintaxe discursiva;

v o(s) discurso(s) presente(s) no texto;

- os principais aspectos ideológicos defendidos nesse(s) discurso(s);

v os principais aspectos ideológicos combatidos nesse(s) discurso(s);

v a posição do discurso hegemônico no texto, com relação aos discursos hegemônicos na sociedade;

v outros aspectos discursivos relevantes.

Mais que simplesmente uma ferramenta de análise de dados, essa perspectiva de análise crítica do discurso acredita que a linguagem é o principal recurso simbólico da construção do social e que dela decorrem as diversas construções das versões de mundo. Construída histórica e socialmente, partese da premissa de que a realidade é fruto do processo de inclusão de alguns fenômenos e exclusão de outros.

O discurso do jornal Estado de Minas (EM) é de legitimação do poder público no tocante às estratégias de criação e gerenciamento dos shoppings populares. Essa legitimação é compreendida em três percursos semânticos, quais sejam: 1. a importância do Código de Posturas do programa Centro Vivo da PBH (Prefeitura de Belo Horizonte); 2. o sucesso empresarial dos shoppings populares; e, 3. os camelôs como os baderneiros e foras da lei. Cada percurso semântico contém diversos elementos que constroem seu significado, como os temas, as figuras e os discursos dominantes.

O primeiro percurso semântico é o que exalta a relevância do código de posturas da $\mathrm{PBH}$, que prevê a retirada dos ambulantes das ruas do centro da cidade. Essa ideia é defendida com afirmações que revelam o grande problema estrutural e de segurança que os camelôs provocam na cidade, como 
se fossem uma chaga: "a ocupação dos espaços públicos por vendedores ambulantes é um dos sérios problemas das grandes cidades" (Estado de Minas, 2003a). Diversas vezes é descrito o transtorno que os pedestres sofrem com a presença dos camelôs nas calçadas: "pedestres prejudicados pelos camelôs" (Matoso, 2003).

No discurso do EM percebe-se a isenção da PBH e demais órgãos públicos quanto à proposição de soluções duradouras para a difícil questão do trabalho informal, representada, em parte, pela atividade do comércio ambulante, como se a solução para esse problema se restringisse à mudança geográfica dos camelôs para um centro comercial, longe dos olhos de todos e da responsabilidade da PBH. Nesse discurso defende-se que é a população quem clama por essas ações. "A cidade quer" para acabar com "a depredação que os camelôs promovem na cidade" (Hybner, 2004). O real objetivo do Código de Posturas, no entanto, não deixa de ser explicitado no discurso do EM, que afirma ser parte de um grande projeto turístico econômico. A preocupação, portanto, não é social, buscando-se a melhoria das condições de vida dos cidadãos e a busca de alternativas para diminuir o desemprego.

Outra questão analisada refere-se ao discurso que reforça a falácia de que a mudança para os shoppings populares (SHPs) irá legalizar a atividade dos camelôs, retirando-os da informalidade. Isso pode ser comprovado através dos vários discursos em que é afirmado, conforme reportagens do EM, que os camelôs que não se mudarem para os SHP permanecerão na informalidade e estarão sujeitos à apreensão de suas mercadorias: "depois da data [de sorteio dos boxes nos SHPs] todos que continuarem nas ruas estarão ilegais e sujeitos a sanções, como o recolhimento de mercadorias" (Ramos, 2004). Ora, essa afirmação apresenta como implícito pressuposto que aqueles que se mudarem estarão legalizados e que não sofrerão apreensões de suas mercadorias. Sabemos, hoje, que a mudança para os SHPs não significou legalização dos seus negócios e que as "batidas" policiais continuaram (e continuarão) acontecendo, como ocorreu em 2005 e 2007, com apreensão de mercadorias no valor estimado de $\mathrm{R} \$ 500$ mil a $\mathrm{R} \$ 4$ milhões de reais, respectivamente.

Uma última questão presente nesse percurso semântico é a isenção de responsabilidade da PBH sobre a questão dos camelôs e de sua mudança para os SHPs. Em 6 de agosto de 2003 (Ramos, 2003b), no período da inauguração, já temos a afirmação de que "o SHP tem o apoio da prefeitura, mas não autorização". Nessa mesma reportagem é apontado que, apesar do projeto ser da prefeitura, conforme previsto no Código de Posturas, o local escolhido para o shopping é privado. Em outra reportagem, do dia 25 de janeiro de 2004, em que é relatada a resistência dos camelôs em saírem das ruas e irem para os 
shoppings, afirma-se que a prefeitura acabou cedendo, o que conota a abertura para negociação dos camelôs com a prefeitura e a tolerância desta em relação à desobediência deles. "A Administração Municipal foi tão permissível que autorizou..." (Estado de Minas, 2004b). Interessante observar que em nenhuma reportagem essa caracterização de compreensão, disposição à negociação e a busca de um ponto ideal para ambas as partes são atribuídas aos camelôs. Pelo contrário, eles são caracterizados como intransigentes e baderneiros, com quem não se tem como estabelecer diálogo, provocando, em alguns momentos, a quebra de negociação com a prefeitura, conforme relatado na reportagem de 15 de janeiro de 2004: "O diálogo está suspenso entre a prefeitura e os ambulantes", pois, segundo o EM, os camelôs não têm controle político sobre sua categoria: os "líderes do movimento não têm controle" (Seleme, 2004a).

A resistência dos camelôs à mudança geográfica é classificada pelo jornal como um "apego ao ponto de trabalho" (Hybner, 2004). Será que é apego o que o camelô desenvolveu com seu ponto de trabalho? E se a proposta fosse mudar o Shopping Diamond Mall de lugar, transferindo-o para a região da rodoviária? A insatisfação de seus comerciantes seria atribuída ao apego ao ponto de trabalho?

Outro percurso semântico presente nas reportagens é o do sucesso do empreendimento dos SHPs. Curioso observar que as reportagens com essa temática foram publicadas no "Caderno Economia" do EM, diferentemente das demais que eram publicadas no "Caderno Gerais". Uma análise detalhada dos discursos desses materiais ajuda a construir a imagem de que os SHPs, em especial o Shopping Oiapoque, são um negócio de sucesso, com vendas altas e maiores rendimentos para os "lojistas". Isso pode ser verificado na escolha das personagens utilizadas para legitimar os discursos hegemônicos: lojistas, microempreendedores, comerciantes, clientes, classe alta, gente chique e jovem. Percebe-se a extinção dos substantivos "camelôs", "informais", "ilegais", "toreros", "ambulantes" e "barraqueiros", já que não são adequados a um shopping. Esse espaço é caracterizado como templo de consumo (Durães e Hybner, 2004) e shopping center (Choucair, 2006). Os boxes são chamados de lojas ou pontos de venda (Choucair e Giannini, 2004). Segundo as autoras, os comerciantes implementaram vendas por cartão de crédito e fazem cursos de gerenciamento e vendas no Sebrae em parceira com a prefeitura e CDL (Câmara de Dirigentes Lojistas de Belo Horizonte). Os clientes recebem tratamento "VIP", com instalação de escadas rolantes e praça de alimentação nos SHPs (Choucair, 2007).

A profissionalização dos empreendimentos é altíssima, fazendo com que seus lojistas lancem campanhas de marketing de final de ano comparáveis às 
dos shoppings centers privados, conforme demonstrado na reportagem de 27 de outubro de 2005 (Mendes, 2005), em que os SHPs se rendem aos sorteios de Natal, com carros, televisores e DVDs. A equivalência dos SHPs aos shoppings centers privados implica no implícito pressuposto de que todos esses estabelecimentos funcionam da mesma maneira e que são concorrentes diretos entre si. Essa afirmativa pode ser corroborada pela reportagem do dia 20 de dezembro de 2004 (Giannini e Reis, 2004), cujo título é "Mais de 1 milhão vão às compras", referindo-se ao número de clientes estimado pela CDL para as compras de Natal. Nesse montante, estão incluídos todos os shoppings da capital. Uma única ressalva feita aos SHPs é uma nota que diz: o "consumidor tem que ter paciência com a pouca simpatia dos vendedores do Shopping Oiapoque". Será que a necessidade de paciência se aplicaria somente ao SHPs? Por que caracterizá-lo como um lugar em que se é mal atendido? Nos shoppings conhecidos como "de elite" isso não ocorre?

A legitimação do discurso de sucesso dos SHPs acoberta, entre outras questões, o sério problema de falta de consumidor enfrentado pelo Shopping Tupinambás. Algumas reportagens revelam que os camelôs (volta-se a chamá-los dessa forma) passam dias sem vender uma só mercadoria e que não ganham dinheiro, nem mesmo para pagar o almoço (Estado de Minas, 2004e; Ferreira, 2005; Lobato, 2006). Na reportagem do dia 12 de março de 2005 (Ferreira, 2005), a equipe de jornalistas afirma que comprovou que "os corredores ficam às moscas e que no segundo andar do Shopping Tupinambás há várias lojas fechadas". Essa mesma reportagem é ilustrada com a foto de uma ambulante com seu caderno de vendas com várias páginas em branco, confirmando que não há saída de mercadorias no shopping.

Esses problemas, porém, não são suficientes para ofuscar o discurso de sucesso atribuído aos SHPs. Como se faz isso? Através de alguns estratagemas: 1. empreendedores competentes; 2 . camelôs fora da lei; e 3. sucesso geral de vendas.

Primeiramente, junto às reportagens em que são apresentadas as mazelas dos SHPs, apresentam-se soluções empreendidas pelos seus administradores, como o investimento em campanhas de marketing, o pedido à BHTrans (Empresa de Transportes e Trânsito de Belo Horizonte) de instalação de uma central de BHBus (ônibus municipal) e a solicitação à prefeitura de instalação da primeira farmácia popular no segundo andar do Shopping Tupinambás. Como se sabe, nenhuma dessas estratégias foi capaz de solucionar os problemas deste shopping.

Em segundo lugar, o jornal apresentou diversas reportagens em que denunciava que os camelôs estavam vendendo os boxes que haviam ganhado 
no sorteio da prefeitura, como em "Camelôs negociam vagas em shopping" (Alencar, 2004), "Camelô vende até vaga" (Seleme, 2004b) e "Denúncia de venda de box" (Estado de Minas, 2004e), por exemplo.

Em terceiro lugar, são apresentadas estimativas de vendas englobando todos os shoppings populares, o que dilui o fracasso de um, no sucesso de outro. Isso pode ser percebido nas reportagens intituladas "Eletrônicos são disputados nos SHPs" (Choucair, 2005), "Belo Horizonte em ritmo de fim de ano" (Campos, 2005) e "Tratamento VIP para consumidor popular" (Choucair, 2007).

Além dessas três estratégias de substituição do discurso do fracasso do Shopping Tupinambás pelo de sucesso dos SHPs, acrescenta-se a reportagem da coluna social "O senhor dos camelôs" (Estado de Minas, 2005), que se refere ao proprietário dos shoppings populares Oiapoque e Tupinambás, que "acolheu os camelôs da cidade" e seu novo empreendimento, o Shopping Metrópole, também popular, porém "mais nacionalista".

O terceiro percurso semântico alinha-se aos anteriores, com vistas à legitimação do discurso dominante. Isso é feito através da desqualificação moral dos camelôs. A seleção lexical deixa isso muito claro, pois eles são qualificados de baderneiros, contrabandistas, fazedores de motins. Em consonância, os temas encontrados são: quebra-quebra, medo, criminalidade, máfia chinesa e violência. Diversas reportagens abordam o descumprimento da ordem da $\mathrm{PBH}$ de proibição de ocupação das calçadas para venda de mercadorias. De acordo com essas reportagens, os camelôs, desobedientes, promovem o medo no centro da cidade e geram prejuízos para diversos lojistas que são ameaçados e obrigados a fecharem as portas de seus estabelecimentos comerciais (Estado de Minas, 2004a; Ramos, 2004; Ramos e Alencar, 2004; Estado de Minas, 2004d; Estado de Minas, 2005; Lobato, 2006; Furtado, 2007).

Outro aspecto que contribui para a marginalização dos vendedores ambulantes é a associação feita entre a máfia chinesa e os camelôs. Em operação que se iniciou em 2003 pela Polícia Federal, diversas reportagens associaram os SHPs com a máfia chinesa, acusando estes locais de serem como "tentáculos" da máfia (Estado de Minas, 2003b), cujos crimes são: contrabando, prostituição, pirataria, tráfico de drogas e extorsão. Com base nessa associação direta entre máfia chinesa e SHP, há a não especificação de qual tipo de crime está sendo associado aos camelôs, nem quais são (ou quantos são) os camelôs criminosos. Assim, constrói-se a imagem de que os camelôs são bandidos.

Essa afirmação encontra eco em outras reportagens em que o combate ao crime de pirataria está diretamente relacionado à atividade dos camelôs. A reportagem do dia 15 de dezembro de 2003 (Estado de Minas, 2003c) ilustra essa questão: "Em Belo Horizonte, a prefeitura promete agir em camelódro- 
mo". Observa-se que, ao se referir ao contrabando, os SHPs são chamados de camelódromos e não de shoppings centers, como nas reportagens em que seu sucesso empresarial é exaltado. Aliás, vale aqui a ressalva do silenciamento sobre produtos contrabandeados ou piratas quando se "comprova" o sucesso de vendas dos shoppings populares.

A diluição promovida pelo jornal acerca das graves denúncias de atuação da máfia chinesa em Belo Horizonte, com os prejuízos econômicos e políticos gerados pelo contrabando e pirataria, acaba promovendo o obscurecimento da real situação em que se encontram os camelôs que, muitas vezes, são oprimidos por integrantes da máfia e ameaçados de morte, conforme citado em uma reportagem (Estado de Minas, 2003b). A hipótese (ou fato) de que os camelôs também são vítimas desta organização criminosa não é ressaltada devidamente pelo EM, ao contrário, o conjunto de reportagens constrói a realidade de equivalência entre crime organizado, prejuízos financeiros e políticos advindos do contrabando e pirataria, e a atividade dos camelôs.

Reforçando a situação de precariedade moral e econômica do trabalho dos "ex-camelôs" quando da mudança para os SHPs, adiciona-se o problema de falta de segurança nos locais em que eles foram instalados. Segundo o Corpo de Bombeiros, todos os shoppings apresentam problemas estruturais que põem em risco a vida dos camelôs e das pessoas que frequentam os espaços (Satuf, 2004). Além disso, conforme reportagem do dia 23 de novembro de 2004 (Estado de Minas, 2004d), o Corpo de Bombeiros afirma que "nenhum SHP implementou o plano de combate a incêndios, além de diversas outras irregularidades e que a prefeitura já foi notificada". Outro problema também desprezado é o descumprimento da gerência do Shopping Oiapoque acerca do total de pessoas que o espaço comporta. O Corpo de Bombeiros afirma que o espaço só comporta 8 mil pessoas/dia, apesar da média atual ser de $15 \mathrm{mil} / \mathrm{dia}$, chegando a até $30 \mathrm{mil} / \mathrm{dia}$ no final de semana. Apesar dessa denúncia e do risco iminente a que trabalhadores e consumidores são expostos ao descumprir-se essa regra, a superlotação do Shopping OI é exaltada como um índice de sucesso do negócio: "Gente chique no camelódromo" (Durães e Hybner, 2004), "Mais de 1 milhão vão às compras" (Giannini e Reis, 2004) e "Tratamento VIP para consumidor popular" (Choucair, 2007).

Entre todas as denúncias feitas, o único estabelecimento fechado por fiscais foi o Shopping das Arábias. Esse shopping é privado e copia o modelo dos SHPs implementados pela $\mathrm{PBH}$, porém não possui nenhum vínculo com ela. Ele foi fechado porque, após um mês de funcionamento, não possuía o alvará. Como se explica o fato de o Shopping Oiapoque que, apesar de não ter alvará após dois anos e quatro meses de funcionamento, não ter sido também fechado? 
Como se não bastassem os problemas de risco de morte que os camelôs e transeuntes sofrem ao frequentarem os SHPs, os camelôs ainda são submetidos a uma administração que comanda os SHPs de forma arbitrária. O preço do aluguel de boxe no Shopping Oi, por exemplo, subiu de R $\$ 100,00$ (Ramos, 2003a) para $R \$ 270,00$ a $R \$ 1.000,00$ (Furtado, 2007). Recentemente, os camelôs organizaram uma passeata em protesto contra a arbitrariedade da administração, pedindo apoio da PBH. Segundo a presidente da associação do Shopping Oiapoque, Maria Goretti de Paula:

Nos puseram [a PBH] dentro do imóvel e agora nos deixam de lado. Na verdade, foi uma armadilha para os camelôs. Estamos nas mãos dos empresários, que aumentam o aluguel da forma que lhes convém. (...) Estamos apenas reivindicando nossos direitos.

(Furtado, 2007)

Em um lugar planejado para abrigar 500 boxes (Estado de Minas, 2004c) e que hoje conta com 1.350 (Furtado, 2007), a resposta da PBH, através de Welton Petrillo, gerente regional do Centro de Comércio Popular (órgão criado pela PBH), às reivindicações dos camelôs é:

Cada shopping popular tem um conselho gestor que se reúne periodicamente com a prefeitura. Nossa obrigação com esses empreendimentos é intermediar demandas, como o reajuste do aluguel e abertura do comércio nos feriados. Não temos a responsabilidade de fiscalizar as ações dos donos dos shoppings, pois são empresas privadas.

(Furtado, 2007)

O grande silenciamento encontrado nesse discurso é acerca das questões que geram a atividade informal dos camelôs. Em nenhuma reportagem, de um total de 83, são tratadas questões como o avanço do desemprego, a baixa renda salarial dos trabalhadores de baixo nível hierárquico nas empresas, (o que os levariam à atividade informal), os altos custos tributários do trabalho formal e, muitas vezes, a baixa escolarização e qualificação do pessoal que encontra no setor informal uma grande oportunidade de trabalho. Além disso, entre os trabalhadores do setor informal, não são questionados temas como a insegurança no trabalho, a marginalidade, a falta de acesso à aposentadoria e direitos legais garantidos ao trabalhador de carteira assinada. O problema dos shoppings populares é apresentado somente como uma questão de mudança geográfica e cumprimento do Código de Posturas da cidade, que só serve para 
transformar o centro da capital em um cartão postal, migrando para as margens os trabalhadores que já são, por assim dizer, marginalizados.

A partir da análise de discurso do Estado de Minas acerca dos shoppings populares, temos que os principais aspectos ideológicos defendidos são: limpeza do Centro da cidade (como se os camelôs fossem a sujeira), investimento em turismo e desocupação das vias públicas para facilitação do comércio lojista. No conjunto, parece haver uma diferenciação discursiva entre "camelô-informal-problema-sujeira" e "lojista-formal-solução-transferência", cujo resultado foi a criação dos shoppings populares de Belo Horizonte, validando esses espaços como o lugar adequado de trabalho.

\section{O shopping ou a objetivação do poder discursivo: o manejo humano}

Indicamos anteriormente como se deu e como ainda se dá a produção discursiva em torno da transferência daqueles trabalhadores informais da rua com destino aos chamados shoppings populares. Vimos que o argumento da revitalização do Centro coadunou para a definição de uma validade social aos novos espaços destinados aos trabalhadores informais. Nesta parte do trabalho, abordaremos a atividade concreta realizada pela prefeitura ${ }^{4}$ no processo de transferência, numa expressão objetiva do discurso de formalidade e de assepsia urbana (revitalização) e, em adição, outras atividades realizadas por membros da sociedade civil ligados à constituição histórica dos, assim chamados, shoppings populares. Ambos os casos produziram consequências diversas configuradas nas novas condições de vida das pessoas nesse espaço comercial.

Se por um lado, como iremos demonstrar, a prefeitura (representativa da figura do Estado) fez uso intensivo de "medidas administrativas" e do seu monopólio da violência materializada na força de polícia, outros fizeram

\footnotetext{
${ }^{4}$ Não queremos dizer, com isso, que a prefeitura era ou é o único e valoroso esforço objetivo do manejo humano em Belo Horizonte, no caso que nos interessa, mas que ela é agente de imputação dos clamores de contribuintes sobre a "poluição" do Centro sem a qual o processo de transferência não teria acontecido exatamente da mesma maneira como ocorreu. Nesse sentido, ela é o agente imprescindível, mas não único, para caracterizar o processo de transferência dos camelôs para os shoppings sob a definição de formal/informal dentro da qual são classificados os homens e mulheres que trabalham nas ruas.
} 
uso de "medidas" tão "informais" quanto a fórmula pela qual são tradicionalmente classificadas as condições de vida impressas nas atividades das pessoas que trabalham nas ruas. É importante, porém, reconhecermos que o fenômeno da transferência, ou do "manejo humano" não se trata de algo novo, ligado às condições sociais e econômicas da atualidade, nem é expressão de um estado como abstração da liberdade e de racionalidade humanas sob a égide de um novo escopo gerencial. Em verdade, tanto na Europa do século XVIII quanto no Brasil do início do século passado, as medidas de manejo humano guardam similitudes com as que estamos apresentando neste trabalho.

Marx (2007), em resposta ao artigo de "um prussiano", denotou que não se pode esperar do Estado, seja ele pertencente a um país político ou não político, medidas ante o pauperismo que não sejam fundamentalmente administrativas. As workhouses na Inglaterra e os depôts (albergues) na França emergiram como fruto das medidas administrativas imputadas pelo Estado diante do pauperismo. Com relação aos depôts, é bastante interessante acompanhar a análise de Marx (2007:8) sobre o interesse e as medidas de Napoleão na tentativa de eliminar a mendicância na França.

Napoleão quis eliminar a mendicância numa só tacada. Ele encarregou as suas autoridades (serviços públicos?) de formular planos para a erradicação da mendicância em toda a França. O projeto demora; Napoleão perde a calma e escreve ao seu ministro do Interior, Crétet; o intima a eliminar a mendicância em um mês; ele diz: "Não se pode passar por essa terra sem deixar marcas que transmitam nossa memória à posteridade. Não me peçam mais três ou quatro meses para obter informações: vocês têm jovens auditores, prefeitos inteligentes, engenheiros de pontes e estradas bastante capazes, coloquem-nos em ação, não adormeçam no trabalho ordinário dos escritórios". Em poucos meses tudo aconteceu. No dia 5 de julho de 1808 foi editada a lei de supressão da mendicância. Como? Através de depôts se transformaram tão rapidamente em penitenciárias que logo o pobre só chegava a esses estabelecimentos através do tribunal de política. E, portanto, clamava M. Noailles du Gard, membro do corpo legislativo: "Eterno reconhecimento aos heróis que asseguram um refúgio à indigência e meios de sobrevivência aos pobres: as crianças não mais ficarão abandonadas, às famílias pobres não faltarão mais os recursos e nem aos trabalhadores o encorajamento e a ocupação. Não tropeçaremos mais no quadro repugnante das enfermidades e da miséria vergonhosa". A última passagem é a única verdade desse panegírico. 
Outro fato histórico que, como esse, demonstra o manejo humano nas cidades nos leva ao Brasil das primeiras décadas do século passado. Sevcenko (1985) relata que a elite do Rio de Janeiro tinha consigo a pretensão de ser cada vez mais europeia, mais francesa, em verdade. $\mathrm{O}$ aumento da frequência das visitas de europeus à cidade apareceu para aquela elite como um sinal de que era preciso mudanças. As damas da sociedade tiveram de aprender um comportamento europeu que incluía, entre outras coisas, os gestos do corpo e da fala. Além do corpo da própria elite, era preciso mudar e reurbanizar o centro da cidade. Lá estava repleto de negros e mendigos, entregues à própria sorte, os quais poluíam o visual e os ares da cidade. A medida lógica veio rápida: expulsaram os indigentes do centro banindo-os para os morros periféricos; a protoimagem das favelas cariocas. Dessa forma, a cidade estava pronta para receber com pompas os ilustres visitantes diante dos quais, e para a elite, a pobreza era sinal de "falta de civilização".

O que esses dois acontecimentos históricos têm em comum, além dos fins óbvios, é a atividade de manejar populações ou, em outros termos, formas comuns de se lidar com problemas sociais dessa ordem. Semelhante a esses exemplos é o processo de manejo dos camelôs das ruas para os shoppings, isto é, livrar o centro da cidade de Belo Horizonte do horror dos vendedores ambulantes: a assepsia urbana; fazer "vivo" o centro "morto" pelos trabalhadores informais. Se o argumento da assepsia é comum a esses três acontecimentos históricos, o da formalidade, no qual se subentende a inclusão econômica e social via translação informalidade/formalidade, demarca a particularidade do manejo humano na atualidade, especialmente no caso em questão. Com o apoio, em parte da mídia e em parte da intelligentsia locais, a prefeitura exerceu seu poder sobre homens e mulheres e suas relações com as coisas (i.e., as mercadorias ilegais, a rua) pelo manejo de um "segmento" social, algo que Foucault (2004a) chamou de "governamentalidade". "Incluir" e "limpar" parecem ser o mesmo que "esconder" e "enclausurar".

\section{Do público ao privado}

A transferência para os shoppings significou diferentes tipos de consequências para os agora chamados "lojistas" (e não mais camelôs). É preciso esclarecer que a mídia, a prefeitura e alguns (e não todos) "ex-camelôs" insistem nessa nova denominação "lojista" por conta da transferência para os shoppings. Essa é uma das expressões mais importantes da produção discursiva em torno do manejo humano concreto em Belo Horizonte, o que implica, evidentemente, 
validação social à nova condição de trabalho no interior dos shoppings. Pudemos perceber pelas entrevistas que realizamos diferentes tipos de vantagens que, em grande medida, validam socialmente essa nova condição. Grande parte dos entrevistados esclareceu que a ida para os shoppings significou melhores condições de negociação e atendimento à clientela, e maior proteção diante das intempéries climáticas. Significou muito profundamente, segundo eles, um melhor tratamento por parte da força policial.

As entrevistas esclarecem, com relação ao último ponto, que o trabalho nas ruas ocorria de forma sempre muito tensa, à medida que, além da movimentação urbana que dificultava o tratamento à clientela, a fiscalização realizava frequentes e intensas incursões. $\mathrm{O}$ trabalho era sempre realizado utilizando a menor quantidade possível de materiais (e.g., bolsas, pequena cadeira, uma tábua que servia de mesa e poucas mercadorias) para permitir a fuga tão logo a fiscalização fosse "avistada" e a minoração das perdas, caso a fuga fosse impossível. O trabalho no shopping permitiu não apenas um melhor tratamento, de modo geral (segundo alguns relatos, antes eram vistos como marginais e agora, não), mas também o reconhecimento e a visita de ilustres homens da sociedade, curiosamente ilustres estes fazedores das medidas administrativas de outrora. Simbolicamente, a presença de tais ilustres nesses espaços contribui para reforçar a validação social do trabalho no espaço dos shoppings:

Aqui vem do mais baixo ao mais alto. Aqui vem político. Ronaldo Vasconcelos já teve aqui, eu tenho foto; já veio José de Alencar. Eu tenho foto com o Ronaldo Vasconcelos, eu tenho foto e tudo o mais. Vêm outros políticos. Vem o Catatau, que é vereador de Sete Lagoas, vem o prefeito de Sete Lagoas aqui. E vem juiz.

(Entrevistado 02)

Por outro lado, nosso estudo permitiu a compressão do significado da transferência para os shoppings em termos concretos. De acordo com o relato do empresário Mário Valadares (Câmara, 2005:138-139), sua iniciativa de construir "os shoppings Oiapoque e Tupinambás teve por objetivo retirar das ruas os comerciantes e fornecer-lhes melhor infraestrutura para realizarem suas atividades, garantindo-lhes, no entanto, os mesmos custos auferidos por eles com o trabalho nas ruas". Um dos inquiridos pela pesquisa, que representa a administração do shopping, corrobora parcialmente com o depoimento supra. Parcialmente, porque indica que a constituição de um dos shoppings se deu em função da imputação do Código de Posturas proibitiva ao trabalho am- 
bulante e não necessariamente a uma atitude benevolente de um empresário diante das condições de vida dos ambulantes na cidade:

Bem, o Mário tinha o imóvel e não sabia bem o que ia fazer nele. Aí, com a aprovação do Código de Posturas da PBH, que proibia aos ambulantes de continuar trabalhando nas calçadas, surgiu a ideia de criar um espaço para receber esses ambulantes, cobrando um aluguel e dando toda a infraestrutura para atender os clientes com segurança e conforto. Dessa ideia surgiu o Shopping Oiapoque.

(Entrevistado 01)

De maneira concreta, a transferência significou a saída do espaço público para o espaço privado. Não no sentido de que os "lojistas" ganharam os seus próprios espaços de trabalho, mas no de que foram levados e inseridos no interior da propriedade privada, interessantemente, pelo próprio manejo humano realizado pela prefeitura. Antes de se tornarem "lojistas", tornaramse inquilinos, mas de maneira especial. A ideia de manter os mesmos custos que incorriam no trabalho nas ruas é mais do que um erro de cálculo: os números são sempre convidados a legitimar novas empreitadas dando-lhes ares racionais. A tendência geral dos preços dos aluguéis não parece ser a da manutenção, mas sim a do crescimento:

Aumentou a boleta, era $\mathrm{R} \$ 100,00$ e foi para $\mathrm{R} \$ 200,00$ e agora é $\mathrm{R} \$ 450,00$. [referindo-se ao aluguel dos boxes]. (...) quando era lá fora, a gente tinha que sair lá de fora e passou, acho que foi a prefeitura, a gente tinha que sair lá de fora e tinha uma data para sair e se não saísse não ia deixar mais ninguém trabalhar. E aí tinha esta proposta para a gente vir aqui para dentro [shopping], e aí todo o mundo teve que vir. E aí depois, quando nós chegamos aqui, falaram que a gente ia ter que pagar aluguel e tudo. No começo não pagava nada, não. No primeiro mês, ninguém pagou nada, não. No segundo mês, já começou a cobrar R\$100,00 e depois foi só aumentando.

(Entrevistado 03)

A inserção no interior da propriedade privada não significou, novamente em termos concretos, apenas a ocorrência do crescimento dos aluguéis e todas as consequências legais associadas ao não pagamento. Significou o destronamento da autonomia do trabalho nas ruas. Em outros termos, salvo os espaços de trabalho com horário flexível, de modo geral a definição do horário de funcionamento é uma atribuição do proprietário da propriedade privada. Um dos relatos indica esse decrescimento da autonomia de trabalho: 
Você paga um aluguel muito alto, você paga condomínio. Você não tem o horário (...) porque você é camelô, você faz o seu horário. Aqui [no shopping], você tem horário para entrar, você tem horário para sair, vendendo ou não vendendo, você tem que pagar.

(Entrevistado 12)

As medidas administrativas imputadas pela prefeitura, sob o argumento da formalidade e da assepsia urbana, significaram o deslocamento das pessoas do espaço público para o espaço privado. Esse manejo humano parece ser respaldado pelos ganhos que os antigos ambulantes usufruiriam deixando as ruas para serem inseridos no interior da propriedade privada na qual, além de se ditar os preços dos aluguéis, dita-se como as coisas devem funcionar ou como o tempo deve ser utilizado no interior desses espaços, chamados shoppings populares. Dessa maneira, a prefeitura conseguiu transformar um problema de ordem social em um problema econômico no interior da propriedade privada: se os "lojistas" não conseguem pagar o aluguel é porque não trabalham direito. Parafraseando Marx (2007), a prefeitura atribuiu a causa principal da informalidade às próprias leis dos informais.

\section{Desarticulação da cumplicidade do informal}

A entrada dos camelôs nos shoppings pode ser explicada por duas questões não excludentes e não exaustivas. Da forma como apontamos antes, a força da lei expressada no Código de Posturas e as vantagens deslumbradas alimentaram a "vontade" de se tornarem "lojistas". No entanto, movimentos infinitesimais mostram o processo de cooptação que inicialmente influenciou a decisão de transferência por parte dos ambulantes e que, já no interior da propriedade privada, alterou, por assim dizer, o "ethos de camelô". Queremos denominar tais movimentos como um processo de desarticulação da cumplicidade do informal necessária à atividade de fazer do centro "morto" um centro "vivo".

De acordo com as notas de campo, pudemos compreender como é (ou era) o "ethos de camelô". Não queremos dizer que esse ethos é uma espécie de programação cultural a partir da qual todos agem mecanicamente. Mas em termos heurísticos, permite apreender um grau significativo de cumplicidade entre os camelôs.

Tal cumplicidade é relatada de diferentes formas e aparece em circunstâncias diversas (e.g., cuidar da barraca alheia na ausência do proprietário, fornecer auxílio de mercadorias faltantes etc.). Existe uma circunstância em 
particular que gostaríamos de aprofundar. Ela é materializada pela luta entre fiscais e camelôs. Se por um lado os fiscais, representativos da força da lei, devem, por um arrolamento ético e profissional, coibir a comercialização de mercadorias ilegais, conforme consta no código formal, por outro, os camelôs, para dar continuidade à atividade "ilegal", precisam se esquivar dos fiscais. Os camelôs desenvolveram algumas táticas de grupo, a arte dos fracos de Certeau (1994) ainda que desenroladas no espaço público. ${ }^{5}$

Os camelôs, durante suas atividades diárias nas ruas, trabalhavam sempre em estado de prontidão. Conforme indicamos antes, trabalhar com poucos materiais poderia significar a diferença entre fugir e ser pego. Além disso, eles contavam uns com os outros para vigiar os que vigiavam (os fiscais) e anunciar as aproximações. Sons e gritos de alarde eram pronunciados no meio da rua através de denominações particulares para indicar uns para os outros o perigo iminente da chegada dos fiscais. De pronto, homens e mulheres arrumavam as coisas como podiam fazer, dadas as condições, e partiam em fuga.

Essa cumplicidade não pareceu ser forte o bastante para permitir que os camelôs se mobilizassem diante da arbitrariedade do manejo humano promovido pela prefeitura com a conivência de outras instâncias da sociedade civil. A cumplicidade das ruas não se transformou em cumplicidade para as ruas. Além das questões que levantamos antes, um movimento informal permitiu que esse "progresso" das ruas para os shoppings ocorresse. Aos olhos da prefeitura, o "Centro Vivo" é realmente um progresso. Progressos assim são feitos, segundo Polanyi (2000), a partir da desarticulação social.

Recorrendo novamente às notas de campo, compreendemos que alguns camelôs receberam boxes gratuitamente para que em troca convencessem os demais camelôs a se transferirem para os shoppings. Esses camelôs foram cooptados a desarticularem "por dentro", fragilizando a cumplicidade existente

\footnotetext{
${ }^{5}$ Certeau (1994:47) esclarece que "muitas práticas cotidianas (...) são do tipo tática. E também, de modo mais geral, uma grande parte das 'maneiras de fazer': vitórias do 'fraco' sobre o mais 'forte' (...), pequenos sucessos, artes de dar golpes, astúcias de 'caçadores', mobilidades da mão de obra, simulações polimorfas, achados que provocam euforia, tanto poéticos quanto bélicos. Essas performances operacionais dependem de saberes muito antigos". Mais adiante, o autor indica que tais táticas são jogadas "com o terreno que lhe é imposto tal como o organiza a lei de uma força estranha (...): a tática é movimento 'dentro do campo do inimigo' (...)" (Certeau, 1994:100, grifos no original). Embora não possamos comparar mecanicamente o espaço público com o "terreno de outro" sendo algo particular, é interessante observar que o público não é um espaço de ninguém, mas é organizado pela força da lei, cuja execução é atribuição da fiscalização, do ponto de vista da própria lei. As condutas dos "camelôs" podem ser vistas como táticas diante da atividade de fiscalização.
} 
entre eles. Depois de instalados no interior da propriedade privada, muitos camelôs tomaram conhecimento que tal prática havia sido realizada, de forma que certa desconfiança se instaurou no lugar daquele ethos anterior.

Essa questão pode ser corroborada pela alteração que se propiciou já no interior da propriedade privada. De camelôs, eles se tornaram "lojistas" inquilinos pressionados pelos pagamentos dos aluguéis sempre ascendentes. No espaço do shopping outra lógica se instaura: a da competição. Devemos compreender que não se pode atribuir essa nova lógica à proximidade geográfica dos "lojistas". Ora, nas ruas a proximidade também era plena e, ao invés da competição, se encontrava a cumplicidade, o "ethos de camelô". A pressão provocada pelos aluguéis e a desconfiança gerada anteriormente entre eles provocou o desenvolvimento de um "ethos de mercado", diferente, portanto, daquele outro:

Muito, muito, muito (concorrido). Aqui é a lei do cão. (...) Por exemplo: tem gente que vende comida a 3,50 ou a 3 reais, a minha é 4,50 , porque tem em cima contador, está em cima de impostos, está em cima de carteira assinada e um monte de coisas. Décimo terceiro, fundo de garantia.

(Entrevistado 12)

Podemos corroborar essa substituição do "ethos de camelô" pelo do "mercado" a partir das consequências progressivas instauradas pela inserção dessas pessoas no interior da propriedade privada sob a égide da competição. Muitos "lojistas" relataram que, com o passar do tempo e com o aumento gradual e arbitrário dos aluguéis, muitos "ex-camelôs" tiveram de abandonar os seus negócios os quais foram comprados dos proprietários dos shoppings por outros empresários em melhores condições de competição, devido às circunstâncias de vida anteriores. A desarticulação social foi necessária para a imputação de uma lógica de mercado ou para a alteração de um ethos por outro mais propício à degradação/transformação do espaço de "ex-camelôs".

O manejo humano via desarticulação da cumplicidade também significa um processo de alteração espacial, uma desterritorialização. Pagés e outros (1990) fornecem a ideia de que essa desterritorialização consiste em separar o indivíduo de sua origem social e cultural, destituí-lo de sua história pessoal para reeditá-la no interior de outro espaço. Se no caso dos autores é a empresa capitalista que empreende tal atividade, no nosso caso parece ser a prefeitura e seu poder de manejar populações. Retirar, limpar o centro, movimentar artificialmente as pessoas significa colocá-las em outro espaço, no interior de uma propriedade privada, intensificando a desarticulação social entre os camelôs, 
fazendo-os deixar de ser camelôs ao passo que se erige um novo ethos, uma forma diferente de se lidar com os companheiros de condição de vida. O "ethos de camelô" significava cumplicidade; o "ethos de lojista" significa competição.

\section{Individualização e articulação do espaço vigilante}

Nossa investigação permitiu apreender a parcialidade dos resultados alcançados pela prefeitura e, simultaneamente, indica um processo de enclausuramento dos trabalhadores no interior dos shoppings populares. Alguns "lojistas" não deixaram de ser camelôs (se é que qualquer um deles deixou) e continuam trabalhando como "toreros" nas ruas da cidade, mas de forma especial.

Como dissemos antes, a condição de trabalhador informal exige habilidades, certas astúcias ou táticas para lidar com a atividade de fiscalização. ${ }^{6}$ Alguns "lojistas" operam clandestinamente antes do horário de funcionamento dos shoppings. Um dos entrevistados relatou que trabalha informalmente na área próxima à rodoviária da cidade pela manhã. Segundo ele, na parte da manhã os fiscais ainda não estão nas ruas.

Essa circunstância ilustra o que o espaço do shopping de fato significa se comparado com o trabalho nas ruas e as táticas que isso implica. Se por um lado há uma "boxerização", por outro há a utilização do espaço pela força policial para exercer um controle mais efetivo sobre as atividades dos trabalhadores informais no interior dos shoppings populares. Nesse sentido, Foucault (2004b) pode nos auxiliar na compreensão dessas duas questões.

O autor esclarece (especialmente nas páginas 117 a 127) o exercício do poder na docilização dos indivíduos no interior de determinados espaços, isto é, a base para uma microfísica de um poder que ele denomina "celular". Ainda, segundo ele, "a disciplina procede, em primeiro lugar, à distribuição dos indivíduos no espaço" (Foucault, 2004b:121) e, para este fim, certas técnicas são adequadas, isto é, a arte das distribuições. Entre as quatro técnicas descritas pelo autor (a "clausura", o "quadriculamento", a "funcionalidade das localizações" e o "intercambiamento"), as três primeiras são muito úteis para uma análise da arquitetura espacial de um shopping popular.

Com relação à primeira técnica, Foucault (2004b:122) esclarece que "a disciplina às vezes exige a cerca, a especificação de um local heterogêneo a

\footnotetext{
${ }^{6}$ Veja-se, por oportuno, nota de rodapé anterior, em que abordamos o assunto com as palavras de Certeau.
} 
todos os outros e fechado em si mesmo. (...) Houve o grande 'encarceramento' dos vagabundos e dos miseráveis; houve outros mais discretos, mais insidiosos e eficientes". Tais encarceramentos insidiosos e eficientes ocorrem, para o autor, nos colégios e nos quartéis e, posteriormente, nas fábricas, mas é interessante observar que ele faz referência ao "encarceramento" dos vagabundos e miseráveis que, no nosso caso, possui conotações diferentes, como iremos mostrar. É possível atribuir aos shoppings populares o mesmo status que Foucault atribuiu aos espaços estudados por ele, por um lado, espaços com ares de fortaleza - que só abriam as portas para a entrada das pessoas e novamente para a sua saída sob cerrada vigilância; do tipo de encarceramento dos "leprosos" - e espaços transparentes, por outro, cuja disciplina é exposta em suas ramificações e é reforçada pelo auxílio de todos os membros da sociedade disciplinar. No nosso caso não se trata de uma cerca, mas de uma definição de espaço, isto é, a demarcação do trabalho possível e legal nos limites de uma espacialidade: o shopping. Ora, as ruas tinham exatamente o sentido oposto: o do "não lugar", das táticas. Os shoppings são, portanto, a demarcação da possibilidade de trabalho e igualmente a negação do "não lugar". Voltaremos à questão mais adiante.

Mas seguindo o autor, "o princípio da clausura", da cercania, não é indispensável. Existe uma segunda técnica mais flexível e fina, isto é, "cada indivíduo no seu lugar; e cada lugar, um indivíduo" (Foucault, 2004b:123): é o princípio da localização imediata ou do "quadriculamento". Se nas ruas a delimitação do espaço de atividade individual seguia os termos da informalidade, nos shoppings cada "lojista" ocupa um lugar específico, ocupação devidamente catalogada nos registros do proprietário do shopping e da prefeitura, cada um possui um número específico (loja 1 , loja 2, loja $3 . .$. área amarela, área azul...), uma diferenciação. Os shoppings não se resumem à demarcação da possibilidade de trabalho, mas também, em seu interior, expressam o quadriculamento na forma de boxes, uma "boxerização". Delimitar o lugar aqui não tem exatamente a conotação de eliminar a vagabundagem pela medição dos méritos e pela utilização dos corpos como em Foucault, mas sim a individualização dos trabalhadores informais via "concessão" de um lugar próprio, devidamente numerado e registrado. Para o manejo humano eficaz também se faz necessário dar "nomes aos bois".

Ainda, segundo Foucault (2004b), uma terceira técnica se desenvolve na medida em que a cerca e o quadriculamento não garantem a distribuição dos indivíduos sobre um aparelho de produção que carece da funcionalidade dos postos, como, por exemplo, os postos de trabalho no interior das indústrias. Obviamente, os shoppings não possuem o caráter de aparelho produtivo 
no plano da "boxerização" (pois não sabemos como é o funcionamento particular no interior das lojas), mas possuem uma funcionalidade desconhecida no período em que o trabalho era realizado exclusivamente nas ruas e a mídia nos auxilia nesta caracterização. Da forma como dissemos antes, no caso dos shoppings não se trata de uma cerca, mas de uma definição de espaço. Isto porque os shoppings não se configuram como fortalezas, mas exatamente o oposto: é a possibilidade do fluxo, da transparência, todos de "fora" podem vigiar; a abertura pela força da lei e da polícia (que nem sempre, como veremos, cumpre a lei).

Nessa direção, nos últimos anos a imprensa de Belo Horizonte tem divulgado matérias e mais matérias sobre as incursões policiais aos shoppings populares em busca de mercadorias contrabandeadas, conforme indicamos anteriormente. Como sempre, a fiscalização ocorre sem anúncio prévio e é esta a sua natureza: o segredo. A fiscalização nas ruas era uma atividade bem mais complicada por conta, principalmente, das táticas grupais que indicamos antes. A definição dos shoppings como a demarcação da possibilidade de trabalho e a "boxerização" permite a funcionalidade e a eficácia às incursões policiais porque: 1 . os trabalhadores possuem um lugar próprio e não estão dispersos nas ruas — os "bois têm nomes"; 2 . as mercadorias estão, em parte, nos depósitos das lojas e não em depósitos dispersos pela cidade; 3. o shopping como propriedade privada está a mercê de ordem judicial; e 4. o espaço permite a penetração dos fiscais por todas as entradas do shopping, diminuindo substancialmente as chances de fuga.

A partir dos relatos que coletamos é possível apreender o funcionamento da fiscalização. A chegada dos fiscais é acompanhada de uma "onda" de fechamento dos boxes. Os "lojistas" ficam escondidos em vão no interior deles. Em uma reportagem recente, o jornal Estado de Minas (Pereira, 2007) indica a fiscalização por outros meios, isto é, realizar a incursão no horário anterior ao funcionamento normal do shopping e, com apoio em ordem judicial, abrir os boxes sem a presença dos "lojistas". A matéria ainda esclarece que numa incursão do dia 8 de maio de 2007, o mandado dava conta do pedido das notas ficais antes da apreensão das mercadorias. Tudo indica que a ação foi feita de forma arbitrária em não conformidade com a lei, que a própria polícia deveria imputar. Resultado: apreensão de 4 milhões em mercadorias "suspeitas":

Na ação de hoje não foram efetuadas prisões. Os policiais cumpriram 111 mandados de busca e apreensão emitidos pela Justiça Federal e outros 61 pela Justiça Estadual. A prefeitura municipal disponibilizou dez caminhões e até o 
início da tarde oito veículos haviam deixado o shopping lotados de mercadorias apreendidas, que foram encaminhadas para depósitos da Receita. Os responsáveis pelo comércio serão intimados a apresentar documentação que comprove a legalidade. Caso contrário, os produtos poderão ser doados ou destruídos. Entre outros crimes, os comerciantes podem ser autuados por sonegação fiscal e pirataria.

(Agência Estado, 2007)

Constatamos, pois, como a utilização do espaço pela demarcação da possibilidade de trabalho e a "boxerização" permite uma funcionalidade à força da lei. Os shoppings são, em detrimento do argumento da formalidade e da assepsia urbana, espaços articulados para o exercício da vigilância (sutil). A questão principal não é a translação informalidade/formalidade com a qual se classifica os trabalhadores e nem tão só eliminar os germes do centro, fazendo do "morto" um "vivo", mas colocá-los no interior de uma propriedade privada, um espaço delimitado de trabalho possível, para ampliar o controle e a vigilância. Muitos "lojistas" temem novas fiscalizações ${ }^{7}$ e é esse o maior efeito de um espaço destinado à vigilância: o medo produz disciplina.

O que fica evidente em nossa análise, parafraseando Marx (2007), é que a prefeitura jamais encontrará nela mesma e na organização social (e ambas são a mesma coisa) a causa dos males sociais. "Todos os Estados procuram as causas nas deficiências acidentais ou intencionais da administração, e por isso procuram o remédio de seus males nas regulamentações administrativas" (Marx, 2007:10). E mais: “quanto mais poderoso é o Estado, quanto mais político consequentemente é um país, menos ele está propenso a procurar as origens dos males sociais e a entender o seu princípio geral no princípio do Estado, isto é, na atual organização da sociedade, da qual o Estado é a expressão ativa, pretensiosa e oficial" (Marx, 2007:11). Pela oficialidade de suas atribuições e ações, a Prefeitura Municipal de Belo Horizonte, no caso do manejo humano, não reconhece a razão do problema nela mesma e pelos argumentos descabidos de formalidade e de assepsia urbana transforma um "problema social" em um "problema econômico" e em um "caso de política" no "interior da propriedade privada". O manejo humano para um espaço de vigilância e a própria constituição de tal espaço como caracterização desse

\footnotetext{
${ }^{7}$ De acordo com a comerciante Heloísa Ferreira, 40, que tem boxe no Shopping Tupinambás, "os comerciantes estão trabalhando com pouca mercadoria, com medo de também serem alvo da fiscalização" (Lopes, 2007).
} 
manejo é expressão da cumplicidade do Estado com o capital e de sua incapacidade fundamental e contraditória de resolver os problemas que ele mesmo pretensamente é encarregado de fazer, pois suprimir toda e qualquer desigualdade social requer a autossupressão do próprio Estado.

\section{Considerações finais}

Tentamos indicar neste trabalho questões ligadas ao processo de transferência que têm sido amplamente evitadas em nome da positividade do trabalho formal. Nosso estudo denota que existem muitas especificidades da atividade de manejar seres humanos, além de seu descabimento.

Se por um lado a atividade realizada pela prefeitura local no manejo humano desembocou na utilização do espaço do shopping para a degradação do "ethos de camelô" e para a vigilância mais precisa ao inserir as pessoas no interior de uma propriedade privada, por outro, o jornal Estado de Minas contribui para dar racionalidade a tal atividade. Ela não apenas não soluciona o problema da informalidade, como significa a utilização mais efetiva da força policial, embora nem sempre as ordens judiciais tenham sido corretamente cumpridas.

O principal resultado de toda a produção discursiva e da atividade de manejo humano foi a transformação de um problema social em um caso de polícia no interior de uma propriedade privada. Resultado que é frequentemente negado tanto pela mídia quanto pelos trabalhos acadêmicos que tratam da gestão de cidades (e.g., Zambeli, 2006). Em verdade, embora tais trabalhos não reconheçam, eles estão filosoficamente comprometidos com a regulação da vida humana que, de Hobbes a Hegel, expressa a racionalidade estatal como algo natural e absoluto. Continuam a apontar a sujeira dos centros das cidades com indicadores ainda mais imundos, repetindo e legitimando as atitudes de Napoleão, da elite carioca no início do século passado e as medidas administrativas do Estado moderno que, mais gerencial, não divisa seres humanos de bois, fazendo-os sucumbir à sua arbitrariedade e incapacidade legitimadas.

O argumento da formalidade é tão descabido quando o da assepsia urbana. Tipificar oscilantemente de camelô ou de lojista, de informal ou de formal serve para, simultaneamente, legitimar o novo espaço de trabalho e questionar a validade do trabalho informal, quase sempre se fazendo esquecer que o trabalho informal não teve origem no fracasso do fordismo ou na industrialização deficiente, mas sim naquilo que antecede a proletarização dos seres humanos nos dias atuais, isto é, a propriedade privada no interior da indús- 
tria. Ora, não existiria trabalho informal na ausência de trabalho formal; um define o outro e a própria definição é uma criação do Estado moderno.

A positividade da formalidade expressada nos discursos acadêmicos, midiáticos e nas medidas administrativas de inclusão social e econômica não significa a superação da pobreza, mas uma consequência lógica da economia de mercado. Caso o resultado fosse sempre o da exclusão, possivelmente a ordem social não se suportaria. Os programas e medidas de inclusão são soluções para manter as coisas exatamente como estão: eterno retorno.

Nosso trabalho, por fim, não é exaustivo, considerando que o manejo humano não terminou em Belo Horizonte. Acompanhamos os movimentos de resistência dos trabalhadores informais diante das circunstâncias de trabalho no interior dos shoppings populares. Tais resistências têm sido materializadas em passeatas e atividades de negociação com a prefeitura. Temos de saber quais os efeitos que tais movimentos irão provocar sobre a vida dessas pessoas.

\section{Referências}

AGÊNCIA ESTADO. Polícia apreende contrabando em shopping de MG. Agência Estado, 8 maio 2007.

ALENCAR, Gislene. Camelôs negociam vagas em shopping. Estado de Minas, Belo Horizonte, 12 ago. 2004. Caderno Gerais, p. 27.

CÂMARA MUNICIPAL DE BELO HORIZONTE. Ata da reunião especial, 26 ago. 2005.

CAMPOS, Luiz Fernando. BH no ritmo de fim de ano. Estado de Minas, Belo Horizonte, 10 dez. 2005. Caderno Gerais, p. 22.

CERTEAU, M. A invenção do cotidiano: artes de fazer. 9. ed. Petrópolis: Vozes, 1994. v. 1.

CHOUCAIR, Geórgea. Eletrônicos são disputados nos shoppings populares. Estado de Minas, Belo Horizonte, 7 maio 2005. Caderno Economia, p. 11.

. Comércio popular vive clima de véspera de Natal. Estado de Minas, Belo Horizonte, 16 dez. 2006. Caderno Economia, p. 13.

. Tratamento VIP para consumidor popular. Estado de Minas, Belo Horizonte, 4 jul. 2007. Caderno Economia, p. 16.

; GIANNINI, Bianca. Aceita-se cartão de crédito. Estado de Minas, Belo Horizonte, 8 ago. 2004. Caderno Economia, p. 3. 
DURÃES, Alfredo; HYBNER, Eduardo. Gente chique no camelódromo. Estado de Minas, Belo Horizonte, 5 set. 2004. Caderno Gerais, p. 21-22.

ESTADO DE MINAS. Shopping popular tira ambulantes da rua. Estado de Minas, Belo Horizonte, 31 mar. 2003a. Caderno Gerais, p. 21.

. Máfia chinesa chega a BH. Estado de Minas, Belo Horizonte, 14 dez. 2003b. Caderno Gerais, p. 23.

. País perde R\$ 160 bi. Estado de Minas, Belo Horizonte, 15 dez. 2003c. Caderno Gerais, p. 16.

. Camelôs são transferidos do Centro. Estado de Minas, Belo Horizonte, 13 jan. 2004a. Caderno Gerais, p. 22.

. Camelôs resistem à mudança de endereço. Estado de Minas, Belo Horizonte, 25 jan. 2004b. Caderno Gerais, p. 17.

. Camelôs voltam à rua. Estado de Minas, Belo Horizonte, 28 jan. 2004c. Caderno Gerais, p. 18.

. Ambulantes disputam vagas. Estado de Minas, Belo Horizonte, 23 nov. 2004d. Caderno Gerais, p. 24.

. Denúncia de venda de box. Estado de Minas, Belo Horizonte, 5 dez. 2004e. Caderno Gerais, p. 22.

. PBH quer ruas limpas. Estado de Minas, Belo Horizonte, 11 mar. 2005a. Caderno Gerais, p. 22.

. O senhor dos camelôs. Estado de Minas, Belo Horizonte, 20 nov. 2005b. Caderno Feminino \& Masculino, p. 03.

FARIA, A. A. M. Interdiscurso, intradiscurso e leitura: o caso de germinal. In: MARI, H.; MACHADO, I. L.; MELLO, R. (Orgs.). Análise do discurso: fundamentos e práticas. Belo Horizonte: UFMG, 2001.

FERREIRA, Pedro. Debandada do Tupinambás. Estado de Minas, Belo Horizonte, 12 mar. 2005. Caderno Gerais, p. 26.

FIORIN, J. L. Elementos de análise do discurso. São Paulo: Contexto, 1989.

FOUCAULT, M. Microfísica do poder. 19. ed. Rio de Janeiro: Edições Graal, 2004a.

. Vigiar e punir. 28. ed. Petrópolis: Vozes, 2004b.

FURTADO, Ingrid. Camelô faz manifestação. Estado de Minas, Belo Horizonte, 15 maio 2007. Caderno Gerais, p. 23. 
GIANNINI, Bianca; REIS, Graziela. Mais de 1 milhão vão às compras. Estado de Minas, Belo Horizonte, 20 dez. 2004. Caderno Gerais, p. 19.

GONTIJO NETO, J. de P.; MACHADO, A. F. O setor informal em Belo Horizonte: estratégia de vida ou de sobrevivência, 2003. 51p. ms.

HELAL, D. H.; NEVES, Jorge A. B. Superando a pobreza: o papel do capital social na Região Metropolitana de Belo Horizonte. Cadernos EBAPE, v. 5, n. 2, jun. 2007.

HYBNER, Eduardo. Retirada de camelôs começa com confronto. Estado de Minas, Belo Horizonte, 14 jan. 2004. Caderno Gerais, p. 21.

INSTITUTO BRASILEIRO DE GEOGRAFIA E ESTATÍSTICA (IBGE). Economia informal urbana 2003. Comunicação social, 19 maio 2005. Disponível em: <www. ibge.gov.br>. Acesso em: 10 ago. 2007.

LOBATO, Paulo Henrique. Camelôs fora das ruas. Estado de Minas, Belo Horizonte, 31 jan. 2006. Caderno Gerais, p. 21.

MAINGUENEAU, Dominique. Termos-chave da análise do discurso. Belo Horizonte: UFMG, 1998.

MARX, K. Glosas críticas ao artigo "o rei da Prússia e a reforma social. De um prussiano". Trad. preliminar Cornélia Hoffmann. Vorwäts!, n. 63, 7 ago. 1844, Belo Horizonte, 2007. ms.

MATOSO, Eduardo de Almeida S. Camelôs. Estado de Minas, Belo Horizonte, 8 dez. 2003. Caderno Gerais, p. 18.

MENDES, Karla. Varejo popular adere a sorteio. Estado de Minas, Belo Horizonte, 27 out. 2005. Caderno Economia, p. 15.

NORONHA, Eduardo G. "Informal", ilegal, injusto: percepções do mercado de trabalho no Brasil. Revista Brasileira de Ciências Sociais, v. 18, n. 53, out. 2003.

ORGANIZAÇÃO INTERNACIONAL DO TRABALHO (OIT). Informe do diretor geral. Trabalho decente nas Américas: uma agenda hemisférica, 2006-2015. In: REUNIÃO REGIONAL AMERICANA 16. Anais... Brasília, maio 2006.

PAGÉS, M.; BONETTI, M.; GAULEJAC, V.; DESCENDRE, D. O poder das organizações. São Paulo: Atlas, 1990.

PEREIRA, E. Deputados visitam shopping popular para apurar denúncia contra ação da polícia. Estado de Minas, Belo Horizonte, 8 maio 2007.

POLANYI, K. A grande transformação: as origens de nossa época. 2. ed. Rio de Janeiro: Elsevier, 2000. 
RAMOS, Mariana. Camelódromo esvazia Oiapoque. Estado de Minas, Belo Horizonte, 5 ago. 2003a. Caderno Gerais, p. 25.

. Camelódromo busca regularização. Estado de Minas, Belo Horizonte, 6 ago. 2003b. Caderno Gerais, p. 22.

. Camelôs invadem o parque. Estado de Minas, Belo Horizonte, 5 jul. 2004. Caderno Gerais, p. 19.

; ALENCAR, Gislene. Camelôs brigam na saída. Estado de Minas, Belo Horizonte, 10 ago. 2004. Caderno Gerais, p. 25.

RIBEIRO, Álvaro Miranda Leite. Responsabilidade social empresarial: percepções e possibilidades. Dissertação (Mestrado em Ciências Sociais - Gestão das Cidades) — Pontifícia Universidade Católica de Minas Gerais, Belo Horizonte, 2005.

SATUF, Ivan; SELEME, Ana Carolina. Shopping Xavante sob risco. Estado de Minas, Belo Horizonte, 11 nov. 2004. Caderno Gerais, p. 25.

SELEME, Ana Carolina. Camelôs resistem à mudança. Estado de Minas, Belo Horizonte, 15 jan. 2004a. Caderno Gerais, p. 20.

. Camelô vende até vagas. Estado de Minas, Belo Horizonte, 14 ago. 2004b.

Caderno Gerais, p. 25.

SEVCENKO, N. As muralhas invisíveis da Babilônia moderna. Óculum Revista da Arquitetura, v. 1, ago. 1985.

ZAMBELI, Paulina Helena Lima. O trabalho informal dos camelôs da região central de Belo Horizonte e a transferência para os shoppings populares. Dissertação (Mestrado em Ciências Sociais) - Pontifícia Universidade Católica de Minas Gerais, Belo Horizonte, 2006. 